\title{
Strain concentration zone along the volcanic front derived by GPS observations in NE Japan arc
}

\author{
Satoshi Miura, Toshiya Sato, Akira Hasegawa, Yoko Suwa, Kenji Tachibana, and Satoshi Yui \\ Research Center for Prediction of Earthquakes and Volcanic Eruptions, \\ Graduate School of Science, Tohoku University, \\ Sendai 980-8578, Japan
}

(Received May 31, 2004; Revised September 29, 2004; Accepted October 22, 2004)

\begin{abstract}
A nationwide GPS array with more than 1,000 permanent stations operated by the Geographical Survey Institute of Japan, has provided many invaluable deformation data such as co- and post-seismic, volcanic, and ongoing secular deformations in the Japanese islands. Based on daily coordinate data of the GEONET stations together with results from a regional network operated by Tohoku University, we derived a map of the strain rate distribution in NE Japan showing that there exists a notable strain concentration zone of EW contraction along the Volcanic Front. The area demonstrates active seismicity including some disastrous earthquakes. Recent seismic tomography studies have revealed the existence of inclined seismic low-velocity zones (LVZ) at depths shallower than $\sim 150 \mathrm{~km}$ in the mantle wedge sub-parallel to the subducted slab. The inclined LVZ reaches the Moho right beneath the Volcanic Front, indicating that the formation of the strain concentration zone is closely related to the rheological structure of the island-arc system.
\end{abstract}

Key words: Strain concentration zone, Volcanic front, Inland earthquakes, GPS.

\section{Introduction}

Surface deformation data, in combination with data of subsurface structure, are essential to understanding the mechanism of occurrence of inland earthquakes. In 1997 and 1998, intensified seismological experiments were carried out to understand the deformation process of the arc crust and its relation to the occurrence of large earthquakes in the northeastern (NE) Japan arc. Many temporary seismic stations were deployed to augment the regional seismic networks (Hasegawa and Hirata, 1999). In cooperation with this project, a dense GPS network was also established in 1997 around Ou Backbone Range (OBR) to directly observe the deformation of the island-arc crust (Miura et al., 2002). OBR runs through the middle of the Tohoku District, NE Japan, in the north-south direction. There exist many active volcanoes and active faults that have caused disastrous earthquakes.

Suwa et al. (2004) improved the reliability in vertical component of displacement obtained by GPS observations by means of the Precise Point Positioning technique of GIPSY software, and estimated spatial distribution of interplate coupling during 1997-2001 from 3-dimensional velocity field using a geodetic inversion method. Their results show strong coupling along the plate boundary off Tokachi and off Miyagi, corresponding to the previously reported locations of asperities (Yamanaka and Kikuchi, 2004).

In this paper, we analyze the GPS site velocites obtained by Suwa et al. (2004) from the dense observation network

Copy right(c) The Society of Geomagnetism and Earth, Planetary and Space Sciences (SGEPSS); The Seismological Society of Japan; The Volcanological Society of Japan; The Geodetic Society of Japan; The Japanese Society for Planetary Sciences; TERRAPUB to reveal present strain field in NE Japan and interpret them together with other geophysical information, such as seismicity and subsurface structure obtained by seismic tomography.

\section{Data Analyses}

A nationwide GPS network, GEONET, composed of more than 1000 stations has been established by the Geographical Survey Institute (GSI) (Miyazaki et al., 1997) and has provided many invaluable deformation data such as co- and post-seismic (e.g. Heki et al., 1997; Nishimura et al., 2000; Miura et al., 2004), volcanic (e.g. Miura et al., 2000; Kimata et al., 2000), and ongoing secular deformations in the Japanese islands (e.g. Sagiya et al., 2000; Miura et al., 2002). Since GPS data we used in a previous study (Miura et al., 2002) were limited to the region between 38 and $40.5 \mathrm{deg}$. north, we extend the study region to north of 36 degree (Fig. 1) to investigate along-arc variation in the characteristics of deformation.

Baseline lengths of GEONET sometimes exceed $50 \mathrm{~km}$ in the OBR because of its mountainous topography. This separation of GPS stations is not short enough to observe deformation related to the occurrence of M6-7 earthquakes. We incorporated continuous GPS stations operated by Tohoku University to complement the location of GEONET stations in the OBR. Our GPS data are sampled every minute and transmitted through the Japanese University Satellite Seismic Telemetry Network System (JUSSTN), a satellite communication system (Urabe, 1996), or a public telephone line using a modem. Collected data are analyzed using a precise point positioning (PPP) strategy of GIPSY/OASIS-II (Zumberge et al., 1997), which has been 


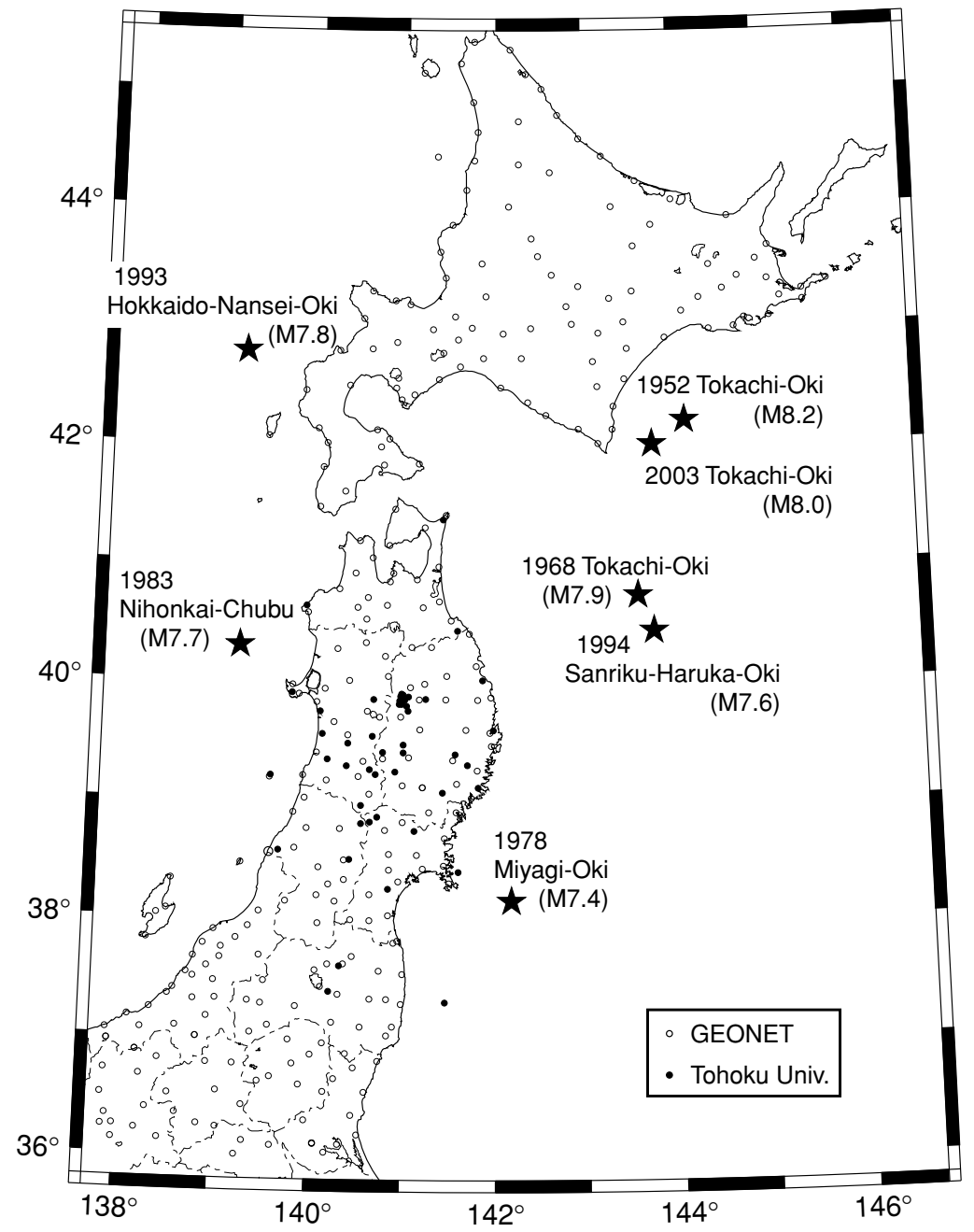

Fig. 1. Map showing the distribution of GPS stations in Tohoku district. Solid and open circles denote the stations operated by Tohoku University and GSI, respectively. Stars denote the location of major interplate earthquakes (After Suwa et al. (2004)).

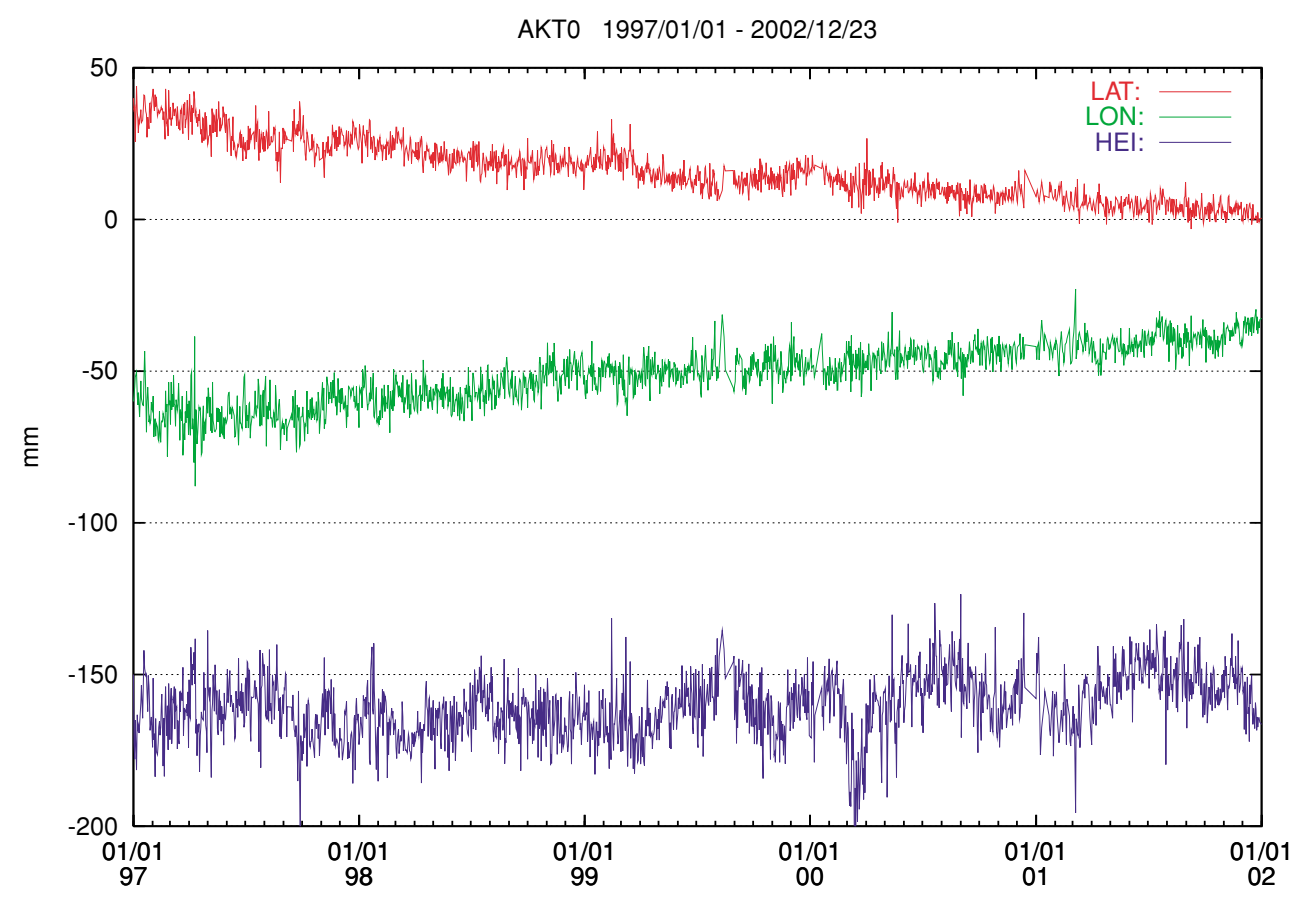

Fig. 2. Time series of variations in coordinates of AKT0 for the period from 1997 to 2001 . Longitudinal, latitudinal, and height components are shown from the top. GPS data are analyzed using a precise point positioning technique of GIPSY/OASIS-II. 


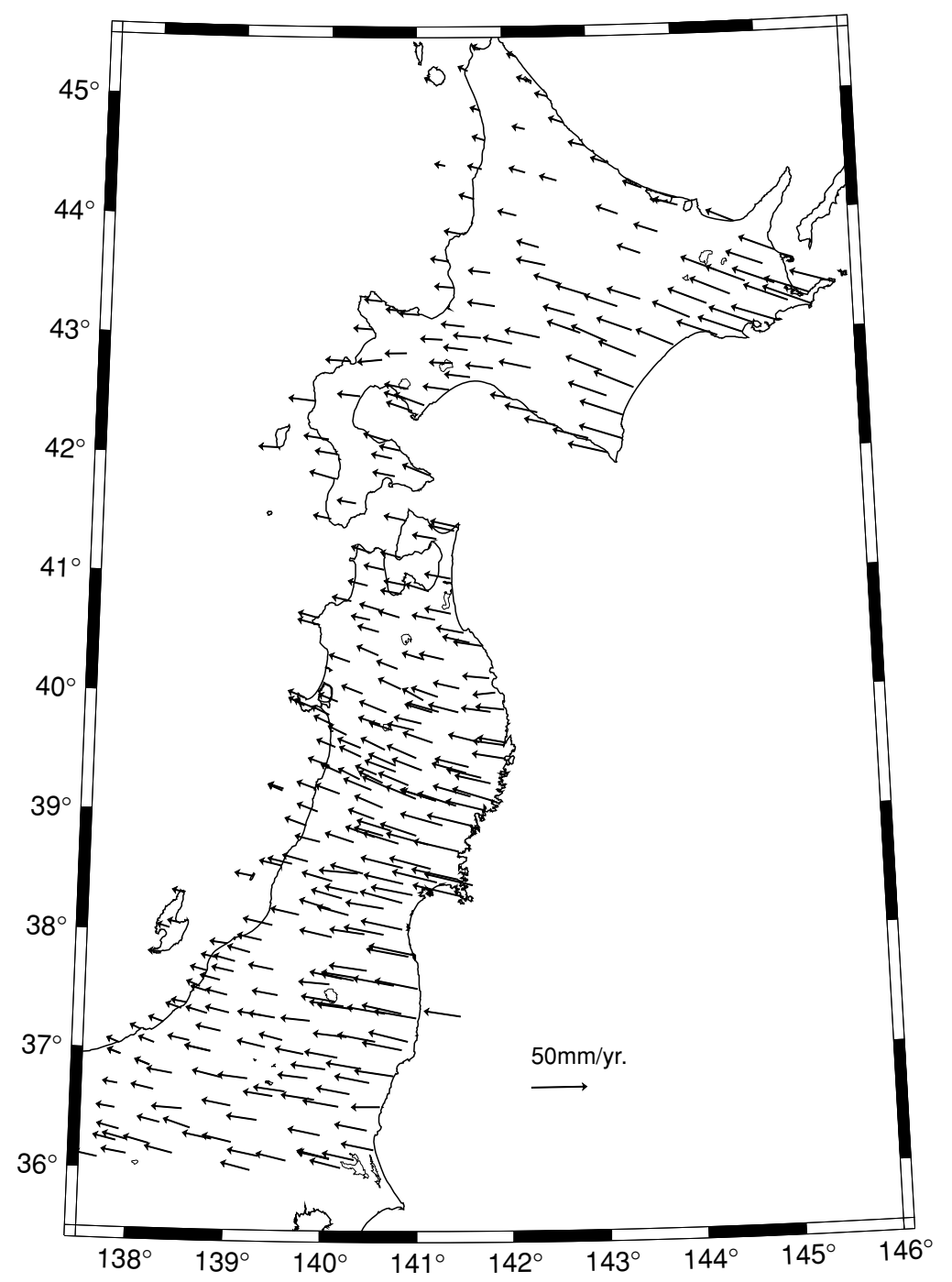

Fig. 3. Horizontal velocities at continuous GPS sites in NE Japan relative to the Eurasian plate for the period from 1997 to 2001 . The velocity data obtained by Suwa et al. (2004) are used.

used in many geodetical and geophysical applications (e.g. Ohtani et al., 2000; Aonashi et al., 2000; Takiguchi et al., 2000). In our previous study, we derived site coordinates for GEONET from SINEX (Software Independent Exchange Format) data provided by GSI and combined them with our own analysis results. In this study, however, we processed all RINEX data both from GEONET and our network for the period from 1997 to 2001 to make site coordinates to be homogeneous and free from distortion due to the mixture of different reference frames and/or different analysis strategies. Figure 2 shows an example of time series of ITRF2000 coordinates derived at station AKT0 located in Akita city, along the Japan Sea coast.

Most of the stations show linear trends in displacement. However, an exception is IWT0 located about $10 \mathrm{~km}$ southeast of Iwate volcano, which activated in the beginning of 1998 and caused distinct dilatational deformation in a denser local GPS network (Miura et al., 2000). IWT0 was displaced about $2 \mathrm{~cm}$ toward the southeast by the activity from February to August, 1998 and also displaced due to the moderate Shizukuishi earthquake with M6.1 which occurred about $10 \mathrm{~km}$ southwest of the volcano (Umino et al.,
1998). This station was not used for the estimation of strain field because its displacement rate was strongly affected by those activities.

\section{Horizontal and Vertical Crustal Deformation Derived by GPS}

Figure 3 shows a map of the horizontal station velocities relative to the Eurasian plate converted from the ITRF2000 velocities derived by the PPP analyses (Suwa et al., 2004). Displacement rates toward the west-northwest are evident at stations along the Pacific coast. This deformation pattern is due to inter-plate coupling between the Pacific (PA) and the North American (NA) Plates (e.g. Nishimura et al., 2000). In addition, there is a contrast in magnitude of displacement along the Pacific coast: larger in the southern part, while smaller in the northern part. This indicates that the interplate coupling is stronger in the south than in the north during the present observation period (Suwa et al., 2003). Post-seismic deformation, clearly observed after the 1994 Far Off Sanriku Earthquake (M7.5), was attributed to after-slip distribution on the plate boundary by means of a geodetic inversion technique (e.g. Nishimura et al., 


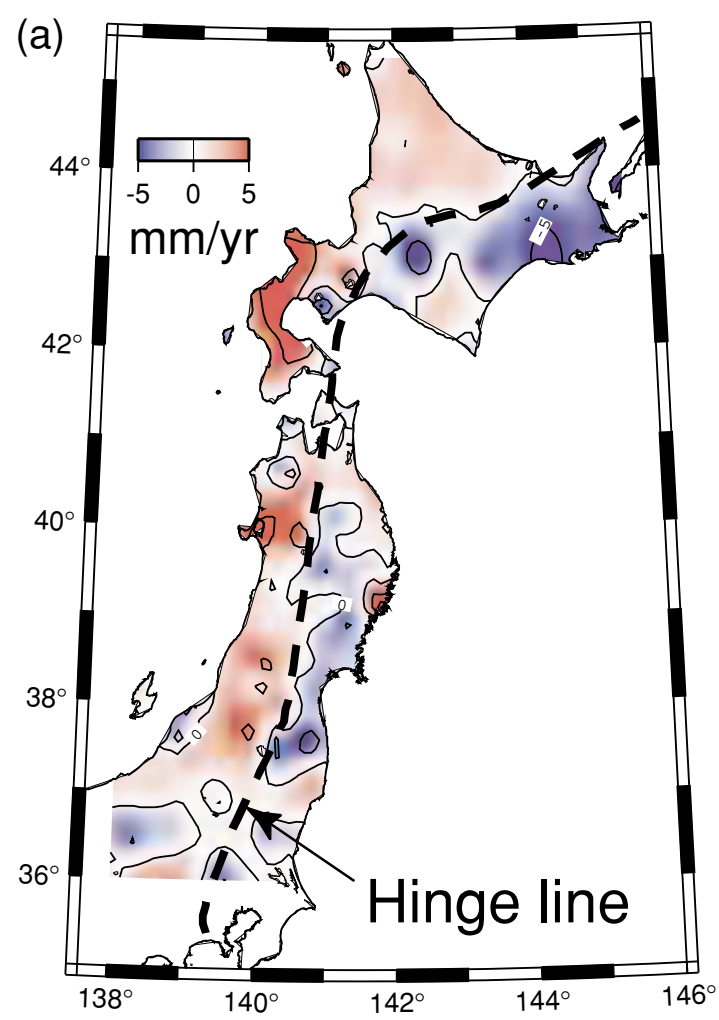

(b)

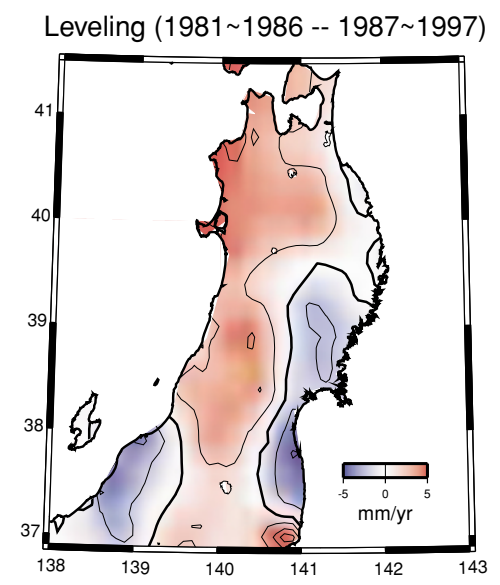

Fig. 4. Vertical velocities (a) as WGS-84 ellipsoidal height changes observed by GPS, and (b) observed by recent GSI leveling survey (After Suwa $e t$ al. (2004)). Contour interval is $5 \mathrm{~mm} / \mathrm{yr}$. Blue and red areas denote subsidence and uplift, respectively.

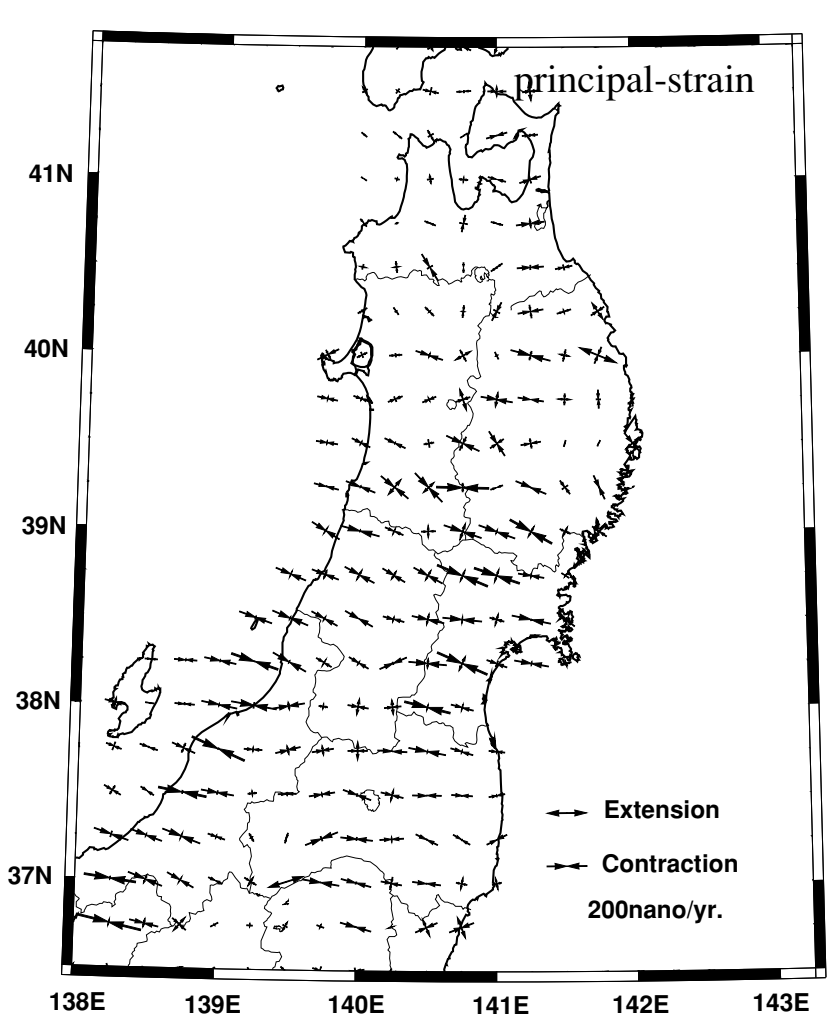

Fig. 5. Distribution of horizontal principal-strain rate for the period from 1997 to 2001.
2000). Smaller displacements along the northern Pacific coast suggest that the northern part of the plate boundary is still on the way to recovering interplate coupling.

The large westward velocities along the Pacific coast become progressively smaller inland, indicating surface deformation caused by inter-plate coupling at the plate interface. The velocity field near the Japan Sea coast may be affected by interaction on the nascent plate boundary between the Eurasia plate and the North American plate (Nakamura, 1983; Kobayashi, 1983) along the eastern margin of the Japan Sea. The plate boundary is sometimes referred as that between the Amurian plate and the Okhotsku plate (e.g. Wei and Seno, 1998), however, the reality of those small plates is still in discussion (e.g. Steblov et al., 2003).

The ITRF2000 site coordinates obtained by Suwa et al., (2004) are subsequently transformed into latitudes, longitude, and heights on the WGS-84 ellipsoid. The vertical velocities shown in Fig. 4(a) are then defined as the rates of the ellipsoidal height with reference to the mass-center of the earth, which is identical to the center of the WGS-84 ellipsoid. It is not necessary to take the reference point on the surface into consideration as in the case of GPS height components from double-difference strategy and leveling surveys.

The resultant vertical velocities near the Japan Sea coast are around zero, or slightly uplifting, whereas those along the southern Pacific coast indicate subsidence. This specific pattern of vertical deformation is in good agreement with the results of previous leveling surveys conducted by GSI as shown in Fig. 4(b) (Suwa et al., 2004). Although the observation period is different, the nodal line runs through 


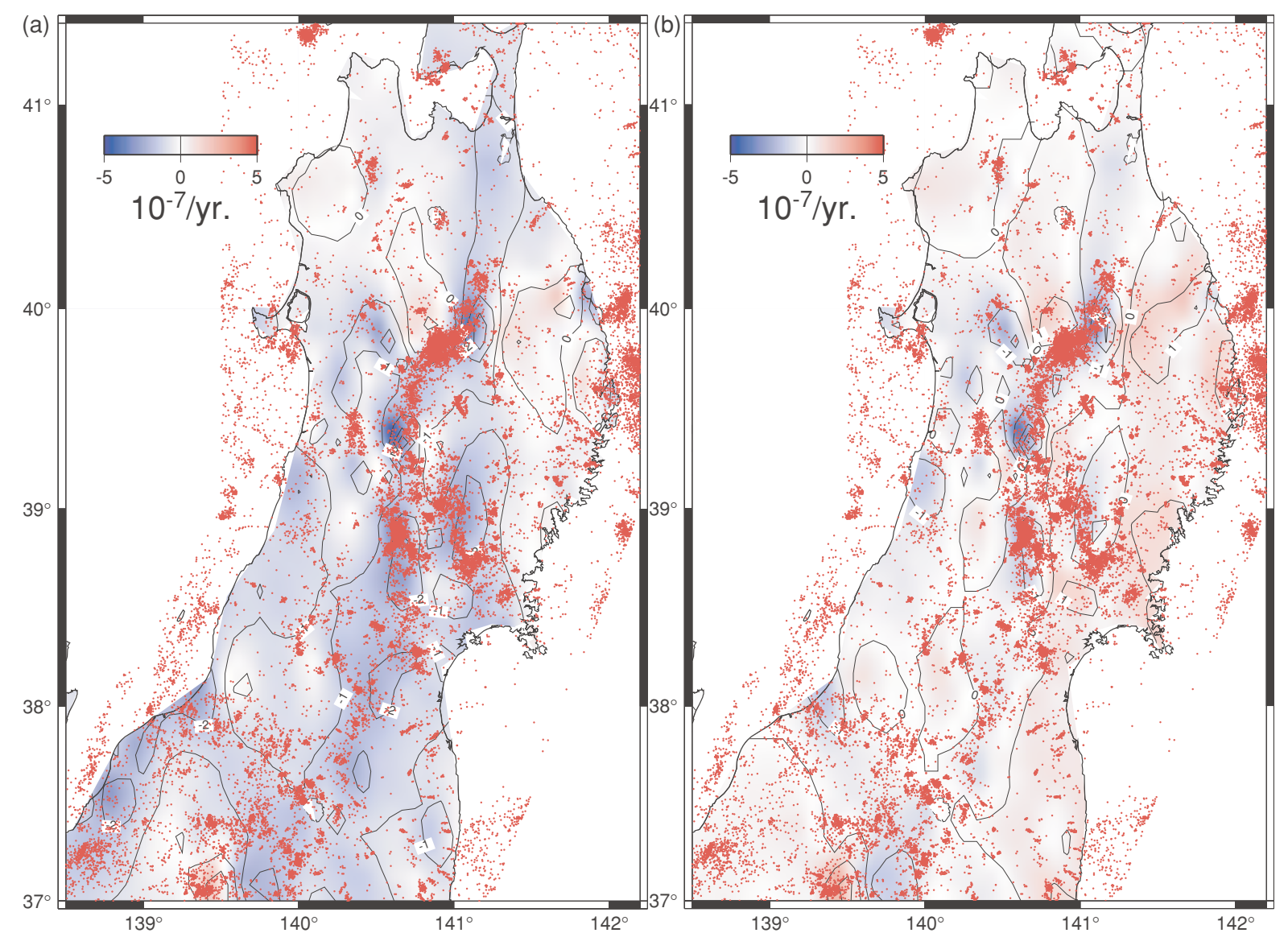

Fig. 6. Horizontal east-west strain rate estimated from GPS observations for the period from 1997 to 2001 with contour interval of 100 ppb/yr. (a) The raw strain rate and (b) the residual strain rate produced by subtracting the effect of inter-plate coupling, which is calculated by the back-slip model estimated by Suwa et al. (2003), from (a). Shallow $(<40 \mathrm{~km})$ earthquakes located by the seismic network of Tohoku University for the same period are indicated by red dots.

around the same area as in the present study, which suggests that the vertical components of velocity derived by GPS are reliable.

\section{Strain Rate Field}

Horizontal velocities for individual stations have been calculated by fitting linear functions to the time-series of site coordinates. Those site velocities are interpolated to produce grid data with constant interval using the programs, blockmean and surface in GMT (General Mapping Tools, Wessel and Smith, 1991). The former reads arbitrarily located 3-dimensional data and outputs a mean position and value for every non-empty block in a grid region defined as its arguments. The latter then reads the output from the former command to produce grid data by applying a parameter, $T$, which controls the roughness of the surface: $T=0$ gives the minimum curvature solution and $T=1$ gives a harmonic surface (Wessel and Smith, 1991). In this study we adopt $T=0.25$, which is often used for potential field data and a block size of 10 minutes by 10 minutes for averaging. The grid data of horizontal site velocities were then differentiated in space to obtain strain-rate estimates.

The distribution of principal strain rates of each grid point is shown in Fig. 5, which is characterized by eastwest contraction and small north-south strain rates except for some localized regions. This agrees well with the fact that the typical focal mechanism of shallow intraplate earthquakes is dominated by east-west compression (Hasegawa et al., 1994; Kosuga et al., 1996). Tada (1986) demonstrated east-west contraction in and around the OBR, together with north-south extension around the Kitakami Mountains, using triangulation and trilateration surveys conducted by the GSI. The east-west contraction in and around the OBR coincides with the present study, while the north-south extension is not obvious in Fig. 5. This may be due to the difference in the observation period and/or the accuracy of the conventional surveys.

In our previous paper (Miura et al., 2002) we demonstrated a similar map of principal strain (see figure 6 in the paper), though it shows rather inhomogeneous distribution. This is partly caused by the difference in the length of time window: from 1997 to 2001 in this paper and from 1997 to 2000 in the previous one. It is obvious that the longer time window produces a reliable site velocity. In addition, we discarded the sites showing localized large velocities clearly due to monument instability such as the case of 960556 (N38.49678, E140.36512). The discrepancy may also reflect the difference in the analysis strategy: we processed RINEX data from GEONET stations and our own in this paper using the GIPSY/OASIS-II software, while we combined coordinates from the SINEX files for GEONET stations and from our own analyses in the previous paper. 


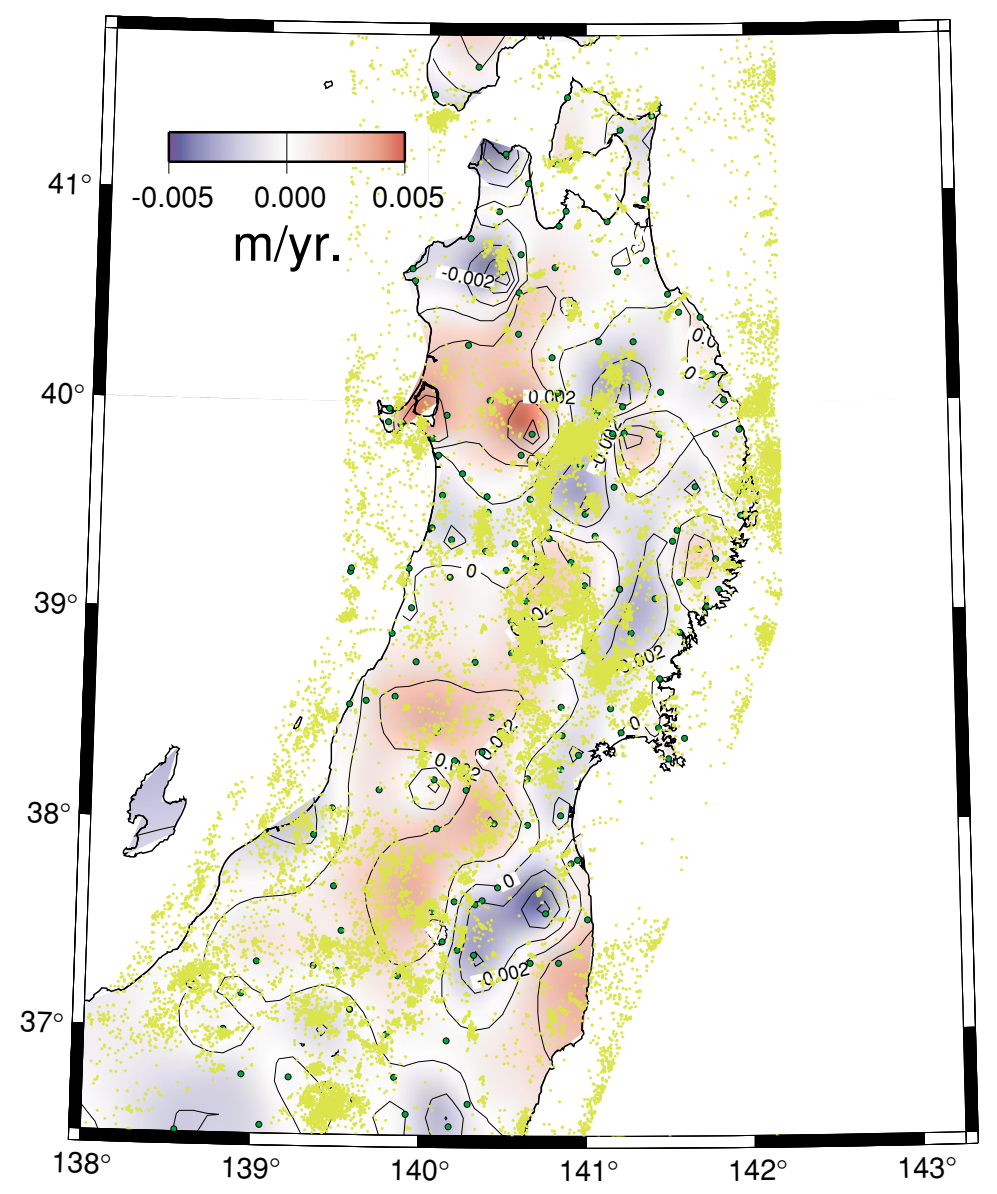

Fig. 7. Distribution of residual vertical displacement velocity. Contour interval is $1 \mathrm{~mm} / \mathrm{yr}$. Dots indicate epicenters of microearthquakes which occurred for the period from 1997 to 2001 with depth shallower than $40 \mathrm{~km}$.

Figure 6 shows the east-west strain-rate field. Along the OBR, or the Volcanic Front, there exists notable concentration of east-west contraction, where the shallow seismicity is relatively active. The area also includes the focal areas of large earthquakes such as the 1896 Riku-u earthquake (M7.2, e.g. Matsuda et al., 1980), the 1970 Southeastern Akita earthquake (M6.2, Hasegawa et al., 1974; Hasegawa et al., 1975), the source region of the M5.9 and M5.7 sequence in 1996, and the 1998 Shizukuishi earthquake (M6.1, Umino et al., 1998). Closely looking at Fig. 6 , there is another zone of strain concentration at the east of the Volcanic Front around 39 degree north, where the shallow seismicity is active, too. Concentration of shallow seismicity, high topography, and relatively large contractional deformation of the crust in the OBR was examined by Hasegawa et al. (2000) using the strain distribution in the direction of plate convergence derived by triangulation/trilateration in the last 100 years. They suggested this feature was caused by a horizontally inhomogeneous distribution of temperature within the crust. In addition, there occurred three major events in 1900 (M7.0), 1962 (M6.5, Kono et al., 1993), and 2003 (M6.4, Okada et al., 2003; Umino et al. 2003; Miura et al., 2004).

\section{Discussion}

Sagiya et al. $(2000,2002)$ investigated the secular deformation field all over the Japanese islands using GEONET data to reveal the detailed characteristics of present-day strain distribution and the existence of the Niigata-Kobe Tectonic Zone (NKTZ) with strain rates larger than 0.1 ppm/yr, where six large earthquakes with M7 or larger have occurred in the last 200 years. Based on numerical experiments, Yamazaki and Seno (2004) showed that the highstrain-rate zone can be reproduced by a model with an effective elastic thickness of $30 \mathrm{~km}$ and with the presence of a localized low-viscosity zone $\left(\sim 10^{18}\right.$ Pas $)$ in the uppermost mantle beneath and seaward of the high strain rate zone. They suggested that the localized reduction in viscosity could be partly caused by serpentinization in the wedge mantle (Kamiya and Kobayashi, in preparation) and this viscosity heterogeneity in the uppermost mantle could be a possible origin of NKTZ.

Vertical crustal deformation provides additional important information to construct models for the strain concentration zone. Vertical deformation in NE Japan shown in Fig. 4(a) should be produced by the tectonic source such as inter-plate coupling, and the response to the tectonic source determined by the elastic and/or viscous rheological structure. The latter may be observed as rather local deformation. Figure 7 shows the residual vertical deformation by subtracting the effect of inter-plate coupling, which is calculated by the back-slip model estimated by Suwa et al. (2003), from the original vertical deformation shown in Fig. 4(a). Because of the relatively larger estimation error 


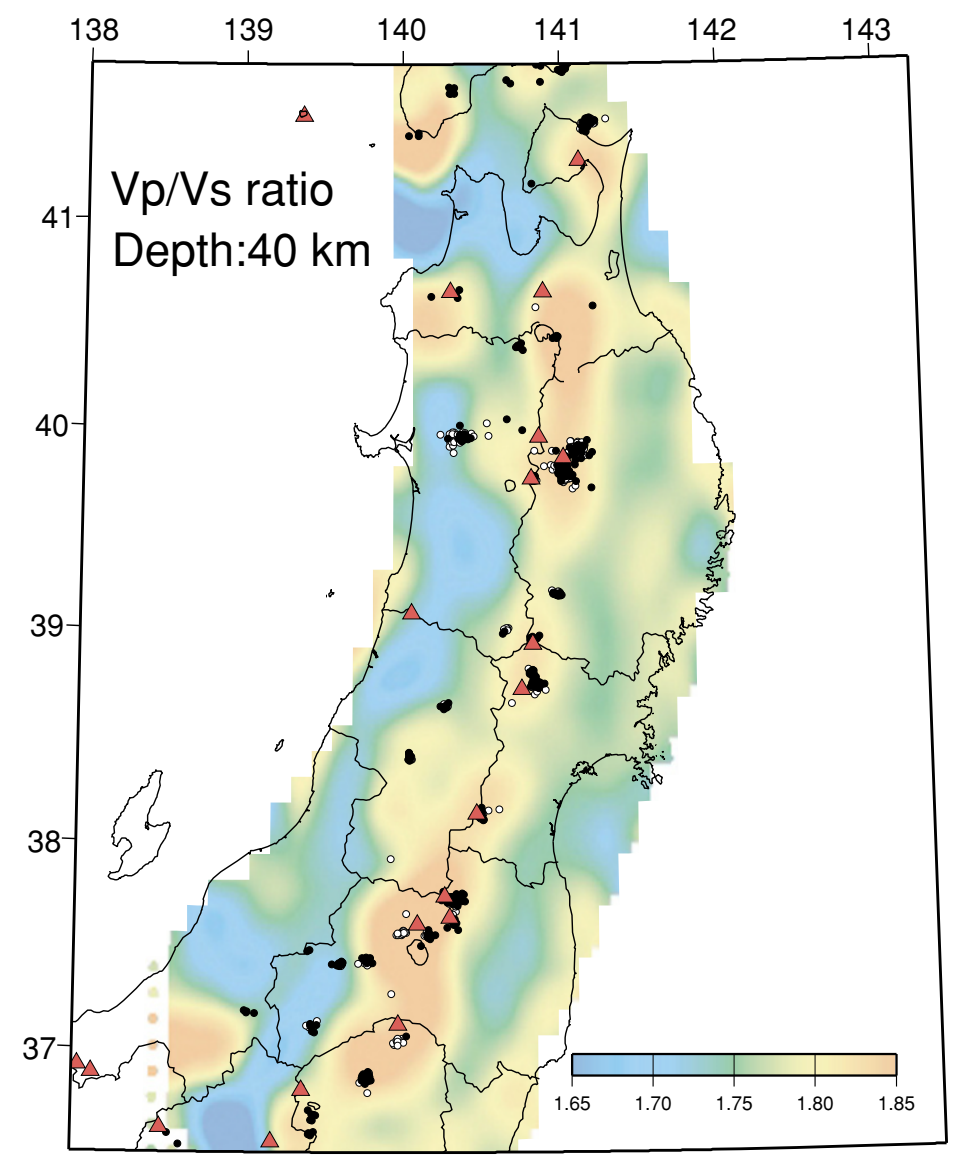

Fig. 8. $V_{p} / V_{s}$ ratio at the depth of $40 \mathrm{~km}$ (Nakajima et al., 2001). Red triangles, open circles, and closed circles show active volcanoes, epicenters of deep low frequency earthquakes relocated by Okada and Hasegawa (2000), and those located by JMA, respectively.

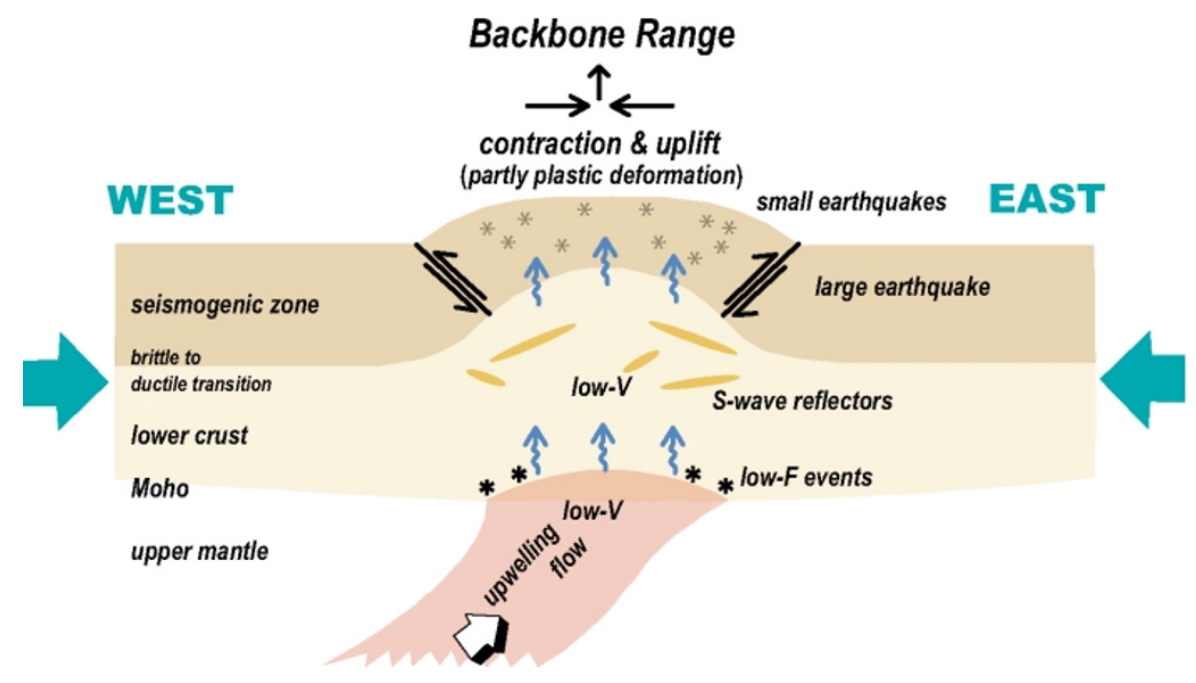

Fig. 9. Schematic illustration of across-arc vertical cross-section of the crust and uppermost mantle, showing the deformation pattern of the crust and the characteristic shallow seismic activity beneath NE Japan (after Hasegawa et al., 2004).

in vertical velocity, the resultant pattern is not quite as obvious as the horizontal strain rate, however, we can recognize uplift along the Volcanic Front and at its western part. This means that the strain concentration zone along the Volcanic Front is also slightly uplifting, and results from some local response to the near EW pressure force.

Nakajima et al. (2001) estimated $V_{p}, V_{s}$, and $V_{p} / V_{s}$ structures beneath NE Japan arc with high resolution to reveal that clear slow anomalies are inclined toward the back arc side in the mantle wedge nearly in parallel to the downdip direction of the subducted slab. Hasegawa and Nakajima (in press) suggested that the anomalies correspond to the upwelling-flow portion of subduction-induced convection. Figure 8 shows the distribution of $V_{p} / V_{s}$ at the depth of $40 \mathrm{~km}$ just beneath Moho discontinuity obtained by Nakajima et al. (2001) and demonstrates that the area of larger 
anomaly runs along the Volcanic Front. The upwelling-flow meets the Moho just beneath the Volcanic Front and magmas thus transported are perhaps stagnated directly below the Moho. Existence of aqueous fluids may weaken the crustal rocks surrounding them. It is expected that this may cause the contraction locally concentrated along the Volcanic Front (Hasegawa et al., 2004).

Comparing Fig. 8 with Fig. 7, we recognize the broad correspondence between the $V_{p} / V_{s}$ anomaly and the local uplift except for the area around $40 \mathrm{~N}$. The discrepancy in this area may be ascribed to rather local deformation with shallow sources such as the postseismic depression caused by asthenospheric readjustment after the 1896 Rikuu earthquake (M7.5) (Thatcher et al., 1980), and the recent volcanic activity of Mt. Iwate in 1998 (e.g. Miura et al., 2000).

Numerical simulations are essential to evaluate the perturbation of elastic and viscous rheological constants, which can explain the pattern of deformation, however, they are left for future studies. Here we just present a speculative model for the deformation process described above as a cartoon shown in Fig. 9. Iio et al. (2004, this issue) constructed a two-dimensional finite element model to examine the stress accumulation process on an inland seismogenic fault. They found that the observed concentration of contraction and uplift around the fault can be explained by the model having the weak zone in the lower crust, suggesting that the weak zone in the lower crust plays an important role in the stress accumulation process on the inland active fault zone. Taking account of the zone of high $V_{p} / V_{s}$ running along the Volcanic Front as shown in Fig. 8, their model can be also applicable for the regional deformation study.

\section{Conclusion}

Five-year observations of crustal deformation by a dense GPS network in NE Honshu reveal a distinct concentration of east-west contraction and upheaval along the Volcanic Front. This feature agrees with focal mechanisms and hypocenter distributions of shallow intraplate earthquakes, the locations of active faults, and the distribution of $V_{p} / V_{s}$ ratio at the depth of $40 \mathrm{~km}$. This suggests that the strain concentration in the area can be related to the weakened structure of the crust and/or upper mantle.

Acknowledgments. We thank the Geographical Survey Institute for permitting the use of GEONET data. The authors are grateful to Keiji Kasahara, Kazushige Obara, and Teruyuki Kato who provided GPS instruments. We also thank two reviewers, Takeshi Sagiya and Roland Bürgmann, whose valuable comments and criticism greatly improved this paper. This research was partly supported by a grant from the Ministry of Education, Culture, Sports, Science ant Technology.

\section{References}

Aonashi, K., Y. Shoji, R. Ichikawa, and H. Hanado, Estimation of PWC gradients over the Kanto Plain using GPS data: Validation and possible meteorological implications, Earth Planets Space, 52, 907-912, 2000.

DeMets, C., R. G. Gordon, D. F. Argus and S. Stein, Effect of recent revisions to the geomagnetic reversal time scale on estimates of current plate motion, Geophys. Res. Lett., 21, 2,191-2,194, 1994.

Hasegawa, A. and N. Hirata, An introduction to the transect of northeastern Japan: Deformation of island-arc and crustal activity, Chikyu, Supl. 27, 5-11, 1999 (in Japanese).
Hasegawa, A. and J. Nakajima, Geophysical constraints on slab subduction and arc magmatism, AGU Geophysical Monograph (in press).

Hasegawa, T., S. Hori, T. Hasegawa, K. Kasahara, S. Horiuchi, and J. Koyama, On the focal mechanism of the Southeastern Akita Earthquake in 1970, J. Seismol. Soc. Jpn., 27, 302-312, 1974 (in Japanese with an English abstract).

Hasegawa, A., K. Kasahara, T. Hasegawa, and S. Hori, On the focal mechanism of the Southeastern Akita Earthquake in 1970 (2), J. Seismol. Soc. Jpn., 28, 141-151, 1975 (in Japanese with an English abstract).

Hasegawa, A., S. Horiuchi, and N. Umino, Seismic structure of the northeastern Japan convergent margin: A synthesis, J. Geophys. Res., 99, 22,295-22,311, 1994

Hasegawa, A., A. Yamamoto, N. Umino, S. Miura, S. Horiuchi, D. Zhao, and $\mathrm{H}$. Sato, Seismic activity and deformation process of the overriding plate in the northeastern Japan subduction zone, Tectonophys., 319, 225-239, 2000

Hasegawa, A., J. Nakajima, N. Umino, S. Miura, and Y. Suwa, Crustal deformation and shallow seismic activity beneath the northeastern Japan arc J. Seismol. Soc. Jpn., 56, 413-424, 2004 (in Japanese with an English abstract).

Heki, K., S. Miyazaki, and H. Tsuji, Silent fault slip following an interplate thrust earthquake at the Japan Trench, Nature, 386, 595-597, 1997.

Iio, Y., T. Sagiya, N. Umino, T. Nishimura, K. Takahashi, and T. Homma, A comprehensive model of the deformation process in the NagamachiRifu Fault Zone, Earth Planets Space, 56, this issue, 1341-1347, 2004.

Kimata, F., S. Kariya, M. Fujita, K. Matsumoto, T. Tabei, J. Segawa, and A. Yamada, Estimated pressure source in Kozu Island volcano, southern Central Japan, with GPS measurements (July 1996-August 1999), Earth Planets Space, 52, 975-978, 2000.

Kobayashi, Y., Initiation of subduction of plates, Chikyu, 5, 510-514, 1983 (in Japanese).

Kono, T., K. Nida, S. Matsumoto, S. Horiuchi, T. Okada, M. Kaihara, A. Hasegawa, S. Hori, N. Umino, and M. Suzuki, Microearthquake activity in the focal area of the 1962 Northern Miyagi earthquake (M6.5), $J$. Seismol. Soc. Jpn., 46, 85-93, 1993 (in Japanese with an English abstract).

Kosuga, M., T. Sato, A. Hasegawa, T. Matsuzawa, S. Suzuki, and Y. Motoya, Spatial distribution of intermediate-depth earthquakes with horizontal or vertical nodal planes beneath northeastern Japan, Phys. Earth Planet. Int., 93, 63-89, 1996.

Matsuda, T., H. Yamazaki, T. Nakata, and T. Imaizumi, The surface faulting associated with Riku-u earthquake of 1896, Bull., Earthquake Res., Inst., Tokyo Univ., 55, 795-855, 1980 (in Japanese with an English abstract).

Mazzotti, S., X. Le Pichon, P. Henry, and S. Miyazaki, Full interseismic locking of the Nankai and Japan-west Kurile subduction zones: An analysis of uniform elastic strain accumulation in Japan constrained by permanent GPS, J. Geophys. Res., 105, 13,159-13,177, 2000.

Miura, S., S. Ueki, T. Sato, K. Tachibana, and H. Hamaguchi, Crustal deformation associated with the 1998 seismo-volcanic crisis of Iwate Volcano, Northeastern Japan, as observed by a dense GPS network, Earth Planets Space, 52, 1,003-1,008, 2000.

Miura, S., T. Sato, K. Tachibana, Y. Satake, and A. Hasegawa, Strain accumulation in and around Ou Backbone Range, northeastern Japan as observed by a dense GPS network, Earth Planets Space, 54, 1,0711,076, 2002.

Miura, S., Y. Suwa, T. Sato, K. Tachibana, and A. Hasegawa, Slip distribution of the 2003 northern Miyagi earthquake (M6.4) deduced from geodetic inversion, Earth Planets Space, 56, 95-101, 2004.

Miyazaki, S., T. Saito, M. Sasaki, Y. Hatanaka, and Y. Iimura, Expansion of GSI's nationwide GPS array, Bull. Geogr. Surv. Inst., 43, 23-34, 1997.

Nakajima, J., T. Matsuzawa, A. Hasegawa, and D. Zhao, Seismic imaging of arc magma and fluids under the central part of northeastern Japan, Tectonophys., 341, 1-17, 2001.

Nakamura, K., Possible nascent trench along the eastern Japan Sea as the convergence boundary between Eurasian and North American plates, Bull. Earthquake Res. Inst. Univ. Tokyo, 58, 711-722, 1983 (in Japanese with English abstract)

Nishimura, T., S. Miura, K. Tachibana, K. Hashimoto, T. Sato, S. Hori, E. Murakami, T. Kono, K. Nida, M. Mishina, T. Hirasawa, and S. Miyazaki, Distribution of seismic coupling on the subducting plate boundary in northeastern Japan inferred from GPS observations, Tectonophys., 323, 217-238, 2000.

Ohtani, R., N. Koizumi, N. Matsumoto, and E. Tsukuda, Preliminary results from permanent GPS array by the Geological Survey of Japan in 
conjunction with groundwater-level observations, Earth Planets Space, 52, 663-668, 2000.

Okada, T. and A. Hasegawa, Activity of deep low-frequency microearthquakes and their moment tensors in Northeastern Japan, Bull. Volcan. Soc. Jap., 45, 47-63, 2000.

Okada, T., N. Umino, and A. Hasegawa, Rupture process of Jul. 26 2003 northern Miyagi earthquake sequence, NE Japan, estimated from double-difference hypocenter locations, Earth Planets Space, 55, 741$750,2003$.

Sagiya, T., S. Miyazaki, and T. Tada, Continuous GPS array and presentday crustal deformation of Japan, Pure Appl. Geophys., 157, 2,3032,322, 2000.

Sagiya, T., T. Nishimura, Y. Iio, T. Tada, Crustal deformation around the northern and central Itoigawa-Shizuoka Tectonic Line: GPS observation and modeling, Earth Planets Space, 54, 1,059-1,063, 2002.

Steblov, G. M., M. G. Kogan, R. W. King, C. H. Scholz, R. Bürgmann, and D. I. Frolov, Imprint of the North American plate in Siberia revealed by GPS, Geophys. Res. Lett., 30 (18), doi:10.1029/2003GL017805, 2003.

Suwa, Y., S. Miura, A. Hasegawa, T. Sato, and K. Tachibana, Inter-plate coupling beneath NE Japan arc inferred from 3 dimensional crustal deformation, paper presented at the Symposium JSG01, 23th General Assembly of the International Union of Geodesy and Geophysics, Sapporo, 8 July, 2003.

Suwa, Y., S. Miura, A. Hasegawa, T. Sato, and K. Tachibana, Inter-plate coupling beneath the NE Japan arc inferred from 3 dimensional crustal deformation, J. Seismol. Soc. Jpn., 56, 471-484, 2004 (in Japanese with an English abstract).

Tada, T., Horizontal crustal strain in the northeastern Japan arc and its relation to the tectonics, J. Seismol. Soc. Jpn., 39, 257-265, 1986 (in Japanese with an English abstract).

Takiguchi, H., T. Kato, H. Kobayashi, and T. Nakaegawa, GPS observations in Thailand for hydrological applications, Earth Planets Space, 52, 913-919, 2000.

Thatcher, W., J. B. Rundall, T. Kato, and T. Matsuda, Lithospheric loading by the 1896 Riku-u earthquake, northern Japan: Implications for plate flexure and asthenospheric rheology, J. Geophys. Res., 85, 6,429-6,435, 1980.

Umino, N., T. Okada, A. Nakamura, J. Nakajima, T. Sato, S. Hori, T. Kono, K. Nida, S. Ueki, T. Matsuzawa, A. Hasegawa, and H. Hamaguchi, Aftershock distribution for the M6.1 earthquake of 3 September 1998 in Shizukuishi, Iwate prefecture, northeastern Japan, Active Fault Res., 17, 1-8, 1998 (in Japanese with an English abstract).

Umino, N., T. Okada, J. Nakajima, S. Hori, T. Kono, T. Nakayama, N. Uchida, J. Shimizu, J. Suganomata, S. S. N. Gamage, A. Hasegawa, and Y. Asano, Hypocenter and focal mechanism distributions of aftershocks of July 262003 M6.4 northern Miyagi, NE Japan, earthquake revealed by temporary seismic observation, Earth Planets Space, 55, 719-730, 2003.

Urabe, T., Basic design of an earthquake telemetering system utilizing a communication satellite, Programme Abstr. Seismol. Soc. Jpn., P22, 1996 (in Japanese).

Wei, D. and T. Seno, Determination of the Amurian plate motion, in Mantle Dynamics and Plate Interactions in East Asia, Geodyn. Ser. v. 27, edited by M. F. J. Flower et al., 419 pp., AGU, Washington, DC, 1998.

Wessel, P. and W. H. F. Smith, Free software helps map and display data, Abstr. EOS Tran. Am. Geophys. Union, 72, 445-446, 1991.

Yamazaki, T. and T. Seno, High strain rate zone resulting from viscosity heterogeneities in the uppermost mantle, Abstracts of 2004 Japan Earth Planetary Science Joint Meeting, T054-008, 2004 (in Japanese).

Zumberge, J. F., M. B. Heflin, D. C. Jefferson, M. M. Watkins, and F. H. Webb, Precise point positioning for the efficient and robust analysis of GPS data from large networks, J. Geophys. Res., 102, 5,005-5,017, 1997.

S. Miura (e-mail: miura@aob.geophys.tohoku.ac.jp), T. Sato, A. Hasegawa, Y. Suwa, K. Tachibana, and S. Yui 